\title{
A FUnÇÃo-AUTOR: EXAMINANDO O PAPEL DO NOME DO AUTOR NA TRAMA DISCURSIVA
}

Leonardo Pinto de Almeida ${ }^{\star}$

\begin{abstract}
Resumo
A partir das contribuições de Foucault, Brunn e Chartier, analisaremos a emergência da função autor na modernidade. Em relação à história, Foucault mostra como a figura autoral foi inventada por meio de uma trama de acontecimentos que vai da responsabilização do agente discursivo à função de referência do saber. Ele indica as características peculiares ao nome do autor, assinalando que ele tem por função delimitar, classificar e organizar o universo dos discursos. O nome do autor é um dos princípios funcionais que regem nossa relação com o saber e com a literatura em nome de um poder e de uma autoridade.
\end{abstract}

Palavras-chave: Autor. Discurso. Modernidade. Emergência.

\section{The Function-author: the analysis of the role of THE NAME OF THE AUTHOR IN THE DISCOURSE}

\begin{abstract}
From the Foucault, Brunn and Chartier's thoughts, we analyze the emergency of the modern author. In relation to history, Foucault shows as the authorial figure was invented through a tram of events that goes of the responsabilization of the discourse's agent to the function of reference. He indicates the characteristics of the name of the author, designating that it has for function to delimit, to classify and to organize the universe of the discourses. This name is one of the functional principles that conduct our relation with knowing and with literature on behalf of a power and of an authority.
\end{abstract}

Keywords: Author. Discourse. Modernity. Emergency.

\footnotetext{
^ Psicólogo, Mestre em psicologia pela Universidade Federal Fluminense, Doutor em psicologia pela Pontifícia Universidade Católica do Rio de Janeiro com estágio sanduíche no Centre de Recherche sur la Lecture Littéraire na Université de Reims Champagne-Ardenne (França). Vínculo: Pós-doutorando na PUC - RJ (bolsa PDJ/CNPq). Departamento de Psicologia. Endereço: Centro de Pesquisas de Energia Elétrica, Área de Conhecimento de Sistemas Acsi, Ilha do Fundão. Avenida Um, s/n - Ilha da Cidade Universitária - Sala D20A. Ilha do Fundão. CEP.:21941590 - Rio de Janeiro, RJ - Brasil - Caixa-Postal: 68007.

E-mail: tazaime@hotmail.com
} 


\section{INTRODUÇÃo}

O presente artigo tem como objetivo analisar o papel do nome do autor na trama discursiva, salientando a invenção histórica e seus elementos discursivos para entendermos seu surgimento na modernidade: partiremos, assim, da obra foucaultiana e sua preocupação concernente ao discurso para constituir uma compreensão do papel que o nome do autor toma em nossa relação de saber e de poder sobre o objeto literário.

Desse modo, veremos, por meio de uma reflexão que aportará sobre textos de Foucault, Brunn e Chartier, as relações que se constroem na modernidade entre o nome do autor, o discurso, o saber e o poder, já que o autor estaria ao lado de uma linguagem de poder, sendo assim uma das manifestações do saber-poder moderno que tanto solapa os modos singulares de expressão e de experiência.

Em O Que é um Autor?, Foucault (1969/2001) traça algumas considerações sobre a problemática da noção de autoria, apresentando sua relação com a escrita e com o discurso. Para ele, a autoria e sua relação com a literatura tem sua emergência no período moderno, devido a uma certa trama de elementos históricos.

Essa noção do autor constitui o momento crucial da individualização na história das idéias, dos conhecimentos, das literaturas, e também na história da filosofia, e das ciências. Mesmo hoje, quando se faz a história de um conceito, de um gênero literário ou de um tipo de filosofia, acredito que não se deixa de considerar tais unidades como escansões relativamente fracas, secundárias e sobrepostas em relação à primeira unidade, sólida e fundamental que é a do autor e da obra (FOUCAULT, 1969/2001, p. 267).

A noção de autor seria então uma "unidade sólida" que demarca territórios específicos no campo das idéias, constituindo um dos mecanismos de ordenação dos discursos. No entanto, como poderíamos delimitar seu surgimento na história do Ocidente?

\section{A ESCRIta LITERÁRIA E A REFERÊNCIA DISCURSIVA}

Durante a conferência de 1969, Foucault retoma a questão da relação da morte com a escrita - questão, também, encontrada em $A$ Linguagem ao Infinito (1963b/2001) - apontando, agora, para a problemática relativa àquele que escreve. O escritor "se apaga", diz Foucault. No entanto, o que seria escrever? E qual seria o papel do escritor nesse jogo entre a caneta e o texto? Seria ele um joguete da escrita?

Na primeira parte dessa conferência Foucault (1969/2001) fala sobre um "desaparecimento do autor", no ato da escrita: "a morte do autor" - expressão de Roland Barthes que faz eco nesse texto foucaultiano. O sujeito que escreve morre, apaga-se em sua singularidade existencial, para que o seu nome tome 
lugar. Ou seja, no escrever, o escritor morre para que seu nome - o "nome do autor" - seja imortalizado: reflexos de uma luta contra a morte. Uma espécie de processo que vai da carne à assinatura. O "nome do autor" é a marca que possibilita unificar, delimitar, referenciar saberes sob a lápide de um território específico: a assinatura.

[...] o autor deve se apagar ou ser apagado em proveito das formas próprias ao discurso. Isto posto, a pergunta que eu me fazia era a seguinte: o que essa regra do desaparecimento do escritor ou do autor permite descobrir? Ela permite descobrir o jogo da função autor (FOUCAULT, 1969/2001, p. 294).

Com isso, poderíamos salientar que o escrever e o desaparecer são verbos intimamente ligados à criação escrita. Contudo, como podemos corresponder um texto a uma singularidade existencial, se ele é fruto de uma luta contra morte? Pergunta grotesca que nos faz pensar no problema referido ao autor e à sua criação. Será por isso que, quando o autor toma a palavra para argumentar a favor de sua obra, seu comentário soa como derrisório ou pouco brilhante? Temos a impressão, ao ouvi-lo falar, de que sua obra tem vida própria e de que seu comentário tenta matá-la, impondo um sentido. O que aconteceria, então, nesse momento mágico chamado escrita? Quem é o seu agente, se por acaso há um agente? Escrever e morrer, empreitada que dá ao texto a glorificação da imortalidade.

Observemos que o escritor marca a posição do sujeito no ato da escrita e que o autor é aquele que tem seu nome imortalizado, tendo propriedades peculiares no jogo dos discursos. A partir da reflexão acerca da problemática referida à função-autor, Chartier, em uma entrevista com Lebrun, afirma que "o inglês evidencia bem esta noção e distingue o writer, aquele que escreveu alguma coisa, e o author, aquele cujo nome próprio dá identidade e autoridade ao texto" (CHARTIER, 1997/1998, p. 32). Nesse ponto, o idioma inglês, segundo Chartier, frisa a diferenciação intentada nesse jogo dual entre escritor-autor, escrita-assinatura.

O escritor é aquele que, por meio da vivência abismal da finitude, é levado a escrever um texto sob a ameaça do vazio deixado pela morte de Deus. ${ }^{1}$ Já o autor é aquele que designa, pelo uso de seu nome, a unidade de uma obra. Dessa diferença podemos salientar que o autor é uma espécie de duplo do escritor. O escritor é mortal e o autor, imortalizado.

Podemos ver aqui que o autor não é o agente da escrita. É, como se a escrita se desse, e o escritor fosse tomado por ela. Como se ele fosse um porta-voz da repetição de linguagem. Escrita sem sujeito? Ou escrita sem agente? Perguntas assustadoras para um humanismo vigente. Na escrita, não haveria agente, pois é a morte seu personagem principal? Ou seja, é a morte que faz a pena deslizar sobre o papel e, daí, surgir uma escrita que transgride os liames do código lingüístico? O nome do autor é, assim, o que resta do jogo de vida e morte no seio da escrita. A função-autor seria o ponto de balizamento que o nome do autor apresenta na ordem dos discursos - para usar aqui a belíssima expressão foucaultiana. Ele faz função - função de delimitação discursiva. 
Entretanto, ao falar desse desaparecimento do autor ou do escritor, Foucault (1969/2001) mostra que existem duas noções que obliteram tal desaparecimento: as noções de obra e de escrita. Noções que escondem a morte do autor, pois apontam para sua provável existência. Afinal de contas, a noção de escrita, comumente entendida, leva, por retroação, para um ponto de uma provável gênese, em que o autor ou escritor seria seu agente. Então, a escrita e a questão "Quem escreveu?" estão relacionadas, escondendo o apagamento do autor ou do escritor. Já a noção de obra, também remete à existência de um autor, de um escritor, pois, se há uma obra, ela seria “De quem?". Pergunta esta que oblitera, de certo modo, o desaparecimento em questão.

A relação entre escrita, obra e autoria, fundamentam uma "mitologia autoral". Brunn (2001), ao analisar a questão da obra, sublinha a correspondência entre esta e o nome do autor. Ela remete ao nome, e não à existência de um indivíduo que, em um certo dia da história, escreveu um texto.

A obra de um escritor, melhor ainda, suas obras (completas), é o resultado de seu trabalho marcado por seu nome; mas esse resultado parece desfrutar de um modo de existência particular, ligado ao modo de existência do nome do autor ele mesmo (BRUNN, 2001, p. 226).

Podemos ver aqui, com Brunn, que a obra e a noção de autoria têm uma relação muito específica, jogando com as peculiaridades do nome do autor e de suas características, em relação à trama discursiva.

Foucault (1969/2001), neste trabalho, questiona-se sobre o lugar vazio deixado por esse apagamento do autor, de onde o nome deste faz função. Dito de outro modo, ele pretende abordar a questão da função-autor pelo viés do estudo de uma "tipologia dos discursos" (FOUCAULT, 1969/2001, p. 286), pois se questiona sobre qual é o papel do nome do autor na ordem dos discursos. Assim, poderíamos sublinhar que a relação da autoria com o discurso aponta para esse modo particular de existência que a obra toma no espaço aberto pelos jogos de linguagem.

\section{TiPOlogia dos discursos E A QUESTÃo DA AUTORIA}

Ao se indagar acerca da problemática relativa à função-autor, Foucault (1969/2001) reflete sobre as diferenças e as similitudes contidas na correspondência entre o nome do autor e o nome próprio. Ele assinala para três características comuns entre os dois: o caráter indicativo, o designativo e o descritivo; porém, elas se dariam, em cada um deles, de maneiras diferentes.

Isso ocorre porque o nome do autor não indica, designa ou descreve, uma existência singular que seria, comumente, discriminada por um nome próprio comum. Ele se corresponde com uma certa gama de textos, designando, descrevendo ou indicando certa relação desse nome com a textualidade. Daí seu caráter primordial de classificação. Este nome baliza, delimita, descreve, unifica uma pluralidade de discursos, sob a égide da assinatura do autor. 
Com isso, podemos pensar que o nome do autor se caracteriza por uma relação particular com os discursos. Em A ordem do discurso, Foucault (1971/1996) aponta os procedimentos que delimitam o discurso. Entre eles, encontramos o nome do autor, que seria um procedimento interno ao discurso que o restringe, o rarefaz. Foucault, aqui, entende o autor "como o princípio de agrupamento dos discursos, como unidade de suas significações, como foco de coerência" (FOUCAULT, 1971/1996, p. 26). O discurso é limitado pelo nome do autor que, com a sua funcionalidade, é utilizado para, assim, unificar diversos saberes discursivos.

Em uma nota, acrescentada, em 1979 ao texto original de 1969, Foucault reafirma o caráter delimitativo do nome do autor, que impede a emergência de uma pluralidade de sentidos.

O autor torna possível uma limitação da proliferação cancerígena, perigosa das significações em um mundo onde se é parcimonioso não apenas em relação aos seus recursos e riquezas, mas também aos seus próprios discursos e suas significações. O autor é o princípio de economia na proliferação do sentido (FOUCAULT, 1969/2001, p. 287).

Ele assinala ainda que o autor não é um elemento anterior a obra, pois ele surge na trama dos discursos, como princípio funcional. Poderíamos dizer que obra e autor fazem parte de um mesmo discurso, não sendo nenhum dos dois anterior a este. Esse nome delimitará, de certa forma, o corpus da obra. E a obra apontará para o autor.

[...] se o autor autoriza seu texto, lhe prestando sua autoridade própria, também pode-se considerar que sua autoridade lhe vem tão somente de sua obra. [...] Assim, a relação do autor com sua obra aparece inicialmente sob uma forma complexa: o autor parece excedê-la, já que ele permite unificar elementos diversos em um só conjunto denominado obra, conjunto este que ele constitui como tal; ao mesmo tempo, ele parece ser inteiramente constituído por seus textos, se sua autoridade é aquela de seus textos (BRUNN, 2001, p. 36).

Aqui podemos observar que o caráter ordenador do nome do autor atravessa os pensamentos de Brunn, - como vislumbramos com o trecho supracitado -, de Chartier, quando este enuncia a relação do autor com a ordem dos livros e de Foucault em sua análise da ordem dos discursos. Não será por acaso que Chartier (1994/1999) comentará esse texto foucaultiano, ao observar a emergência histórica da figura do autor e sua relação com a ordenação do mundo dos livros.

Brunn (2001) concorda com essa maneira de conceber o nome do autor, como marca de um discurso particular, em que a assinatura torna-se sinônimo de um certo poder, de uma certa autoridade sobre o texto e sobre o sentido que dele se tirará. Por isso, a assinatura de um texto, segundo ele, é atravessada pela questão do poder, pois esse nome garante, identifica, autentifica o texto, dandolhe a qualidade marcada pelo nome que a designa. Podemos ver, desse modo, que 
o caráter organizador do nome do autor aponta para o trabalho interpretativo do qual passa a ser - em uma época determinada da história - um elemento-chave. "O autor é o nome dado ao ponto de partida do trabalho interpretativo, e não o ponto de chegada no qual se desempenha este trabalho" (BRUNN, 2001, p. 32). Ponto de partida para a interpretação, pois devemos dar à leitura, a liberdade da apropriação textual. Liberdade contida, por ser situada em um mundo - o mundo dos livros - no qual existem elementos que viabilizam e ordenam certos caminhos de leitura. O nome do autor seria um desses exemplos, pois ele não diz, imperativamente, qual é o caminho que deve ser tomado, mas nomeia aqueles que seriam equivocados se escolhidos.

No entanto, esse modo de funcionamento discursivo, designado pelo nome do autor, demanda, segundo Chartier (1999/2001), "critérios, noções e conceitos particulares" para que ele surja em um tempo determinado da história ocidental.

\section{Autoria, história e MOdernidade}

Foucault (1969/2001), em O Que é um Autor?, retoma as considerações acerca da transgressão, contidas em Prefácio à Transgressão (1963a/2001), A Linguagem ao Infinito (1963b/2001) e Linguagem e Literatura (1964/2000), para apontar a emergência da função-autor.

Se há uma escrita que transgride as convenções literárias, morais e sociais, como a maquinaria social se relacionaria com ela? Se há transgressão, quem transgride? Esta é uma pergunta pertinente que surge em uma sociedade cuja transgressão não pode ser aceita sem penalização. Foucault (1969/2001) circunscreve esse problema, afirmando que, se há transgressão, inventa-se um agente transgressivo para ser devidamente punido, servindo, assim, de exemplo. É dessa necessidade de punição da transgressão contida na escrita - entendida aqui como ato - que a função-autor surge na história ocidental.

A “apropriação penal dos discursos" seria a conceitualização foucaultiana que se remete à noção da escrita como um ato suscetível de punição. Esta apropriação nada mais seria do que a captação do discurso transgressivo pelo enlace dado por um nome - no caso, o do suposto agente da transgressão: o autor. $\mathrm{O}$ suposto agente é nomeado para ser punido, pois seu ato - o ato de escrever - é passível de penalização.

Assim, podemos salientar que a relação da transgressão com a idéia de responsabilização é um acontecimento de extrema importância para a gênese da "função-autor" na modernidade.

Chartier (1994/1999), em A ordem dos livros, discorda da datação histórica dessa apropriação penal dos discursos, afirmando haver casos de penalização mediante a nomeação de agentes da escrita - autores - antes do século XVIII. Contudo, em um debate com intelectuais mexicanos, intitulado Cultura Escrita, Literatura e História (1999/2001), ele sublinha a importância da noção de originalidade em relação a esse novo modo de se deparar com a tarefa de escrever, surgida na modernidade. 
Brunn (2001) e Foucault (1969/2001) sinalizam para a conexão das noções de responsabilização da escrita - a apropriação penal dos discursos - e a de propriedade intelectual, em suas indagações acerca da gênese da autoria na modernidade. A função-autor, como já apontada, surge pelo enlace punitivo do ato transgressivo da escrita. A responsabilização pelo escrito surge, primariamente, aos direitos sobre este. "É preciso observar que essa propriedade foi historicamente secundária, em relação ao que se poderia chamar de apropriação penal" (FOUCAULT, 1969/2001, p. 274).

Em relação a esse caráter genético secundário da noção de propriedade, não há discordância alguma entre Foucault (1969/2001), Chartier (1997/1998) e Brunn (2001). Em todos eles há a afirmação de que a propriedade é uma invenção posterior à responsabilização. É como se o dever viesse primeiro do que o direito. Como se o transgressor fosse apontado antes do proprietário.

A propriedade intelectual surge, então, como um segundo enlace do discurso escrito. Uma reafirmação que responde a pergunta "De quem é a obra?". No entanto, observemos mais de perto as conseqüências dessa indagação específica.

A partir do pensamento foucaultiano, podemos pensar que o período entre o final do século XVIII e o início do XIX, caracteriza-se por uma escrita eminentemente transgressiva, não possuindo mais o caráter de relato, tão característico da produção de uma obra de linguagem - escrita do período anterior ao século XVIII. Se a escrita, então, passa a não reproduzir mais uma palavra anterior, de que maneira poderíamos pensá-la?

Não tendo mais naquele que escreve um mero porta-voz de uma palavra prévia, a escrita é abandonada a ela mesma. Este abandono faz surgir a indagação acerca de seu agente com mais fervor, pois se ela é transgressiva, quem é o transgressor? - primeiro momento. Porém, continuemos. Se ela não é mais uma repetição de uma palavra anterior que serve de modelo, como ela se dá? Resposta: ela se torna uma escrita fundada na força de seu ato, ou seja, ela passa a ser entendida como um ato carregado de originalidade - segundo momento que fundamenta a invenção do autor-proprietário. Dito em outras palavras, as obras de linguagem tem sua gênese calcada nas palavras de Deus e da tradição, enquanto a escrita do período moderno se fundamentaria na idéia de originalidade. Chartier, respondendo a uma questão levantada por Lebrun, tratando da problemática relativa à emergência da função-autor, concorda com tal fato, pois afirma que "da Idade Média à época Moderna, freqüentemente se definiu a obra pelo contrário da originalidade. Seja porque era inspirada por Deus. [...] Seja porque inscrita numa tradição" (CHARTIER, 1997/1998, p. 31). A originalidade é uma forte noção evidenciada no século XVIII, que alicerça o direito do autor - ciência jurídica cujo objeto é a propriedade intelectual.

Podemos observar, com isso, que, no século XVIII, surge a idéia relativa à propriedade intelectual, justificada e fundamentada pela lei - o direito do autor. A relação entre "nome do autor" e obra passa a ser questão de direito. Brunn (2001) mostra que na gênese desse conceito estão as noções de direitos e responsabilidades. Todavia, os direitos do autor sobre sua obra não caracterizam a primeira 
dimensão jurídica surgida historicamente, pois eles ocorrem após o enlace do discurso entendido como transgressivo - "apropriação penal dos discursos" - que marca a responsabilização do autor pela escrita como ato passível de punição. Então, como pensar o surgimento da noção de propriedade intelectual? Quais são os elementos ocorridos na história ocidental para que ela tenha sua emergência?

Chartier (1999/2001) frisa que a invenção do autor-proprietário teve seu advento devido a certos acontecimentos históricos ocorridos no século XVIII. Poderíamos pensar que esta invenção se deu por um enlace discursivo, porém, agora, com finalidades diferentes de sua apropriação penal. Chartier (1999/2001) afirma que foram os livreiros e seus advogados que inventaram o autor, visto como proprietário da obra. Foi nesse momento, segundo ele, que o trabalho do autor passou a prevalecer em sua valorização, sobre as tarefas dos outros operários do livro - livreiro-editor, editor, comentador, censor.

Os livreiros londrinos e franceses do século XVIII inventam, então, o autor-proprietário, para poderem ter uma propriedade incontestável sobre a obra, antes cedida a eles pelo autor. Se o autor é o proprietário primordial da obra, o livreiro passaria a ser, no ato da compra do escrito, seu dono, tendo, por isso, o direito de fazer quantas cópias quisesse. O que os livreiros intentavam, porém, não foi o conseguido; em vez disso, o autor passou a ser o real proprietário de sua obra, e, por conseqüência, a ter direitos sobre ela. Apropriação penal e propriedade material são elementos calcados sobre as noções de transgressão e originalidade que possibilitaram a emergência da função-autor.

A luta dos livreiros-editores por seus privilégios de cópia circunscreve uma época conturbada entre a tentativa do Estado de abolir suas vantagens e o remetimento à figura do autor como proprietário primordial da obra. Nesse período, observamos a criação de leis relacionadas à proteção da propriedade intelectual, fundamentadas nas noções de trabalho e originalidade.

Sendo assim, a conexão entre a transgressão e a originalidade indica que a invenção da função-autor perpassa um movimento que estaria entre a punição de um ato e a legalização de um direito.

Como se vê aqui, podemos estabelecer relações entre os pensamentos de Chartier (1997/1998) e de Foucault (1963b/2001; 1964/2000), indicando o século XVIII como marco, pois, a partir desse momento, a tarefa daquele que escreve parou de ser entendida como relato de uma palavra precedente, passando a ser compreendida como um ato original, observando o escritor como fonte da qual emana a obra - teoria do gênio criador.

No entanto, como entender a noção de autor em relação aos diversos campos de saberes? O nome do autor teria o mesmo peso em todas as disciplinas? Qual seria sua relação com a literatura? 


\section{A escrita literária, transgressão e literatura}

Em O Que é um Autor?, Foucault (1969/2001) salienta a diversidade de uso da função-autor no campo dos saberes. Ele ratifica que não são todos os discursos que necessitam da atribuição à figura do autor. No entanto, quando atribuídos, os discursos - sejam eles filosóficos, científicos ou literários - se diferenciam pela relevância dada ao autor, não ocorrendo, assim, uma universalização de uso da função.

[...] a função-autor não é exercida de uma maneira universal e constante em todos os discursos. Em nossa civilização, não são sempre os mesmos textos que exigiram receber uma atribuição (FOUCAULT, 1969/2001, p. 275).

Podemos observar, com isso, que, em se tratando da atribuição do discurso ao nome do autor, há uma prevalência de certos campos de saberes em relação a outros, em determinados momentos da história. Foucault (1969/2001) assinala, por exemplo, que às obras "literárias", antigamente, não era imprescindível a atribuição de seu discurso a um autor - a questão da autoria não se colocava para elas. Entretanto, os discursos "científicos" precisavam ser remetidos a um autor para a valorização da obra, dando-lhe, desse modo, um caráter de verdade.

Entretanto, os discursos literários na modernidade, segundo ele, marcam a necessidade intrínseca de um arremetimento ao nome de um autor. Literatura e autoria passam a "jogar" juntos na modernidade. Um jogo que se associará à dinâmica relacional do saber e do poder. Por meio desse movimento, literatura e autoria se unem, tornando-se indissociáveis. Foucault (1969/2001) aqui, apresenta, timidamente, a importante conexão entre a função-autor e a literatura - alicerçada no período que sucede o século XVIII. Entretanto, há uma grande relevância nesse fato, se enviada à problemática da escrita, conceitualizada em outros textos da obra foucaultiana.

Antes do período moderno a escrita era fruto de uma reverência a uma palavra prévia que fazia dessa tarefa uma repetição de algo já dado. A escrita se debruçava sobre aquilo que "é", por isso seu caráter de relato. Se há apenas a repetição de uma palavra anterior ao próprio escrever - essa atividade vista como uma exposição do que já está dado de antemão - este não necessita fazer referência a um agente, a saber, um autor, por ela se manifestar como a reedição das palavras da tradição e da Verdade Revelada. Esta é a obra de linguagem.

Nos textos “A Linguagem ao Infinito" (1963b/2001), "Linguagem e literatura" (1964/2000) e “A Loucura, a Ausência da Obra" (1964/1999), Foucault define a obra de linguagem, mostrando a relação entre ela e a retórica, já que ambas contam com a existência de uma palavra anterior ao ato da emissão da mensagem. Ela seria a repetição dessa palavra anterior, tendo assim um princípio de decifração prévio ao ato criativo, apontando para uma relação de passividade entre a obra e a linguagem, já que se caracteriza como uma rememoração ou um relato. Nela se manifesta a representação, a repetição das palavras divinas e da tradição. 
Todavia, quando essa palavra prévia pára de reger a escrita, quando surge o esvaziamento da Verdade Revelada e das palavras da Tradição, o ato de escrever não é mais direcionado por sua repetição. A escrita passa a repetir a própria linguagem, a própria atividade de recusa, a própria relação com o vazio deixado pela morte - agora sem o respaldo de uma palavra modelo. Será por isso que a morte de Deus, evento que transforma nossa relação com a linguagem, aponta para uma tarefa de criação contínua e de recusa às palavras anteriores à experiência. Esta escrita, surgida na modernidade, terá um caráter ativo de recusa a todo o tipo de tradição, passando a ser entendida como uma atividade transgressiva que visa à recusa de um já-dito.

Como podemos pensar, a literatura e a função-autor têm seu começo nesse momento em que a escrita se remete à transgressão. A literatura seria a atividade que transgride os ditames dos códigos lingüísticos tradicionais, e a função-autor seria o produto de uma amarração dessa atividade transgressiva. Daí, a interdependência entre os dois conceitos. Em L'auteur, Brunn (2001) concorda com o fato da evidente indissociabilidade relacional entre o nome do autor e a literatura.

$\mathrm{Na}$ nossa prática de literatura, a presença de um nome de autor parece ser a passagem indispensável ao nosso reconhecimento da literatura. Não há texto literário sem autor, não há literatura sem autor (fictício ou real, escondido ou exibido, vivo ou morto), pois as duas noções não são mais separáveis: para inscrever textos na literatura, nós nos contentamos de transmiti-los sob o nome do autor (BRUNN, 2001, p. 12).

Em A ordem dos livros, Chartier (1994/1999) aponta para a existência, desde a Idade Média, de atribuições de autoria à textualidade, e observa o fato de não haver exclusividade relacional entre autoria e literatura, o que é correto. No entanto, a função-autor anunciada por Foucault, a partir do momento em que ela emerge na história, atrela-se a essa figura transgressiva, chamada literatura. A história da literatura nada mais é do que a história de uma repressão - contida na idéia tão contraditória de uma tradição literária - marcada pela bandeira fincada no chão de um nome que territorializa uma conquista - no caso, o nome do autor.

Brunn (2001) esclarece essa evidência histórica, delimitada por Chartier, fazendo alusão a duas figuras de autoridade referidas ao nome do autor - a autorité e o authorship. A autorité estaria relacionada à importância dada ao nome do autor no período que antecede o século XVIII. Ela remete à noção de auctoritates que evidencia uma relação entre o nome e a tradição - a autoridade, representada por esse nome, não é uma autoridade sobre o texto e o seu sentido e, sim, aponta para uma tradição da qual faz parte. Logo, a autorité designa uma autoridade de tradição. No entanto, a segunda figura de autoridade - o authorship - comprova a idéia foucaultiana de uma nova forma de escrita, surgida no século XVIII que, no jogo entre a transgressão e a originalidade, possibilita a emergência da literatura, da função-autor e da inseparabilidade entre esses dois elementos. O authorship 
seria a autoridade dada ao nome do autor, que se calca na noção de originalidade. É pela comprovação lógica do agente da escrita que se evidencia o caráter original da tarefa do autor. Essa noção de autoridade está intimamente ligada ao fundamento do direito autoral.

Com esse ponto, podemos aproximar o pensamento foucaultiano da reflexão de Brunn, para apontarmos que pode haver até relação entre a figura do autor e a textualidade, antes do período moderno, mas esta ligação assinala para uma idéia relativa a uma escrita aliada à tradição e uma leitura que procura evidenciar os traços tradicionais contidos na escrita.

A função-autor marca uma diferença. Ela estaria, então, ligada ao authorship que designa uma nova correspondência entre escrita/nome do autor e leitura/ sentido do texto, pois o nome do autor passa a ter, a partir do século XVIII, aproximadamente, um papel diferente na trama dos discursos. Este nome abrange um grupo de operações complexas que fundamentariam sua vinculação particular à ordem dos discursos e, conseqüentemente, à dinâmica do saber-poder moderno.

\section{FUnÇÃO-AUTOR E SUAS PROPRIEDAdES NA TRAMA DISCURSIVA}

Perguntando-se sobre a questão da atribuição discursiva do escrito - o que o leva a enunciar a terceira e, por conseguinte, a quarta característica da função-autor - Foucault salienta que o nome do autor não indica a posição de um indivíduo, e sim sinaliza para um grupo de "operações complexas" que possibilitam a articulação e a emergência da função, como "ser de razão" (FOUCAULT, 1969/2001, p. 276).

Com isso, ele indica que a atribuição comumente referida a um indivíduo não é senão uma "projeção" sobre a atividade da escrita, de caracteres "psicologizantes". Esta é a essência da idéia de biografia, pois ela reenvia a pergunta sobre o escrever a homens de carne e osso, frisando suas aventuras e mazelas existenciais. Brunn (2001) nota que o endereçamento à vida do autor cria uma "mitologia autoral". Esta mitologia representa as relações discursivas, de poder e de saber calcadas sob à égide do nome do autor, territorializando as produções de linguagem.

Biografia: fato interessante que evidencia a gênese de uma "mitologia autoral", aliando a noção de obra à escrita de um indivíduo. Esta seria uma questão de uma curiosidade leitora? Pois, como haveria um arremetimento a uma individualidade se a escrita acontece e o nome do autor reafirma a morte e não a vida? Indagação obscura que nos leva, novamente, à idéia de uma escrita sem agente. Se não há agente, como glorificar uma individualidade, uma existência?

A função-autor tem seu uso referido a uma trama de "operações complexas" que o articulam à "ordem dos discursos". Foucault (1969/2001) destaca um texto de São Jerônimo - De viris illlustribus - para apontar a proximidade entre a crítica moderna e a exegese cristã, em se tratando da problemática relativa à atribuição discursiva da obra a um autor. 
Nesse ilustre texto da exegese cristã, São Jerônimo aponta quatro operações que sustentam e legitimam a atribuição de uma obra a um autor. Cada uma delas estando relacionada, intrinsecamente, a um problema específico.

A primeira operação vê o autor como "nível constante de valor" (FOUCAULT, 1969/2001, p. 277) ressaltando que o nome do autor se articula na trama discursiva para que os textos entendidos como inferiores, sejam descartados do corpus da obra, devido à suspeita de não fazerem parte desta, realmente. Esta operação, como se pode pensar, está atrelada à concessão de valores aos textos, sendo o autor uma espécie de sistema de medida para sua eventual valoração.

A segunda entende o autor como "campo de coerência conceitual ou teórica" (FOUCAULT, 1969/2001, p. 277). Esta operação tem, como questão primordial, a contradição. O nome do autor serve para delimitar a obra sobre um campo, no qual não haja contradição entre os textos que a compõem.

A terceira refere-se ao autor como "unidade estilística" (FOUCAULT, 1969/2001, p. 277). A questão que sustenta esta operação é a do estilo. O nome do autor designa uma maneira singular da expressão escrita - no caso, o estilo -, colocando-se fora do espaço de sua obra aqueles textos que não possuem sua marca característica.

A quarta e última operação, anunciada por São Jerônimo, delimita o corpus de uma obra, apontando o autor como "momento histórico definido e ponto de encontro de um certo número de acontecimentos" (FOUCAULT, 1969/2001, p. 277). O nome do autor marcaria um espaço temporal, em que sua obra foi criada. Ela seria composta somente de textos que datam do período da existência do autor, estando fora do corpus da obra, os textos de datação diversa.

Foucault (1969/2001) salienta que a crítica moderna se utiliza de modalidades similares para o entendimento do problema em questão.

Os quatro critérios de autenticidade segundo São Jerônimo (critérios que parecem bastante insuficientes aos atuais exegetas) definem as quatro modalidades segundo as quais a crítica moderna faz atuar a função autor (FOUCAULT, 1969/2001, p. 278).

Isto ocorre porque a crítica moderna entende o autor como princípio de delimitação da obra. Ela observa que o nome do autor organiza o corpus da obra, por operar na trama discursiva, como unidade de valoração entre os componentes da obra, princípio de extirpação das contradições, marca de uma estilística e demarcador da história intrínseca à obra.

Brunn (2001), em seu texto L'auteur, frisa que o nome do autor delineia, organiza e autentifica o corpus de uma obra, instaurando relações entre textos diversos. A esta característica do nome do autor de balizar uma conexão entre os textos que, subseqüentemente, farão parte de sua obra, Brunn chamou de "paratextualidade". 
O nome do autor é um princípio de classificação e organização dos escritos, instaurando uma unidade que restringe os discursos no seio de uma obra estabelecida - ordem dos discursos, ordem dos livros.

No entanto, Foucault (1969/2001) chama a atenção para outro problema que designaria assim, a quarta característica da função-autor: a questão relativa aos signos gramáticos encontrados na obra. Esses signos - "pronomes pessoais, advérbios de tempo e de lugar, conjugação de verbos" -, segundo ele, apontam para a existência de um autor. No entanto, a real aceitação desse envio mostraria uma certa ingenuidade, pois esses signos não funcionam da mesma maneira "nos discursos providos da função autor e naqueles que dela são desprovidos" (FOUCAULT, 1969/2001, p. 278).

Com isso, podemos ver que a função-autor não designa a existência singular daquele que escreve, e sim delimita uma teia de discursos sobre um nome. Este pode ser confundido com os signos designativos de uma existencialidade, pois a escrita aponta para um abismo entre a vida e a morte. Entretanto, a escrita provida da função-autor - a literatura sendo um de seus exemplos mais ilustres - não aceita o entendimento de que aquele sujeito, designado pelos signos em questão, seja o escritor. Questão que nos remeteria de novo à problemática da bibliografia e da "mitologia autoral".

\section{7. À guisa de CONCLUSÃo}

Neste artigo definimos a noção de autoria, inserindo-a na problemática histórica e apontando para suas peculiaridades discursivas. Com isso, pudemos observar que essa questão é atravessada por muitas dimensões e problemas.

A função-autor habita o universo dos discursos. Podemos nos referir a ela sob diversos pontos relevantes. Contudo, ela surge devido a uma captura de discursos composta por diversas dimensões: a "legal" - relacionada à noção de responsabilização; a "jurídica" - referida ao problema da propriedade; a "estética" - marcada pela problemática da originalidade; e a "referencial" - que aponta para o nome do autor como princípio de ordenação na trama discursiva.

Observa-se, com isso, que a idéia de transgressão, como motor da atividade literária, atravessa todas essas dimensões. Ela possibilita a observação de que a escrita possui uma dimensão legal e outra jurídica, que enlaçam o fluxo de produção; uma estética e outra referencial, que marcam a atribuição de um discurso específico a um nome. Todas essas dimensões capturam o movimento transgressivo.

Entretanto, podemos ainda pensar em uma dimensão ontológica que vislumbra a atividade transgressiva da escrita no próprio momento que a faz surgir, a saber, na criação e em seu embate com a morte.

Outro ponto que devemos salientar são as características particulares que o nome do autor toma na trama discursiva. Este nome representa um poder, uma autoridade. Ele tem função de delimitar, classificar e organizar o universo dos 
livros e dos discursos. Ele funciona como príncipio que impede a proliferação interpretativa, impondo uma ordem intrínseca ao universo discursivo. $\mathrm{O}$ autor nasce historicamente para brecar a transgressão criativa e se fundamenta discursivamente para filtrar as interpretações, delimitando assim o meio discursivo.

Podemos concluir sublinhando o aspecto relacional do autor, do saber e do poder. Ainda hoje, mesmo depois das críticas sofridas no século passado à sua funcionalidade, o nome do autor continua exercendo seu papel de classificador e organizador de saberes em nome de certo poder. Seu uso corrente, nas discussões acadêmicas, por exemplo, evidencia de que forma o saber-poder moderno se manifesta através de índices e mecanismos discursivos que impõe o valor do que deve ou não ser discutido.

Assim, a referência ao autor não é, de modo algum, ingênua em uma discussão desse tipo, pois ela implica uma relação estreita entre o saber e o poder. Poderíamos ainda afirmar que o saber-poder ligado à noção de autoria solapa a experiência singular, oblitera a interpretação particular, intentando impedir a proliferação discursiva na modernidade.

\section{Notas}

1 Em "Prefácio à transgressão", Foucault entende a morte de Deus como o acontecimento que transforma os modos dos homens de experienciar a vida e, por conseqüência, a linguagem, fazendo emergir uma nova forma de escrita que será uma recusa de todo tipo de tradição: a literatura. Para um melhor aprofundamento da relação entre a literatura, a experiência moderna e a morte de Deus. Cf. FOUCAULT (1963a/2001; 1963b/2001) e ALMEIDA (2002). 


\section{REFERÊNCIAS}

ALMEIDA, L. P. O problema da autoria: internet, literatura e ontologia. 2002. Dissertação (Mestrado)-Universidade Federal Fluminense, Niterói, 2002.

BRUNN, A. L'auteur, textes choisis \& présentés par Alain Brunn. Paris: GF Flammarion, 2001.

CHARTIER, R. A aventura do livro: do leitor ao navegador (1997). Tradução de Reginaldo Carmello Corrêa de Moraes. São Paulo: Unesp, 1998.

. A ordem dos livros: leitores, autores e bibliotecas na Europa entre os séculos XIV e XVIII (1994). Tradução de Mary Del Priori. Brasília: Universidade de Brasília, 1999.

. Cultura escrita, Literatura e História (1999). Tradução: Ernani Rosa. Porto Alegre: Artmed, 2001.

FOUCAULT, M. A ordem do discurso (1971). Tradução de Laura Fraga de Almeida Sampaio. Lisboa: Loyola, 1996.

. A Loucura, a Ausência de obra (1964). In: Ditos e Escritos I: Problematização do sujeito: Psicologia, Psiquiatria e Psicanálise. Rio de Janeiro: Forense Universitária, 1999. p. 190-191.

. Linguagem e Literatura (1964). In: MACHADO, R. Foucault, a filosofia e a literatura. Rio de Janeiro: J. Zahar, 2000. p. 137-174.

- Prefácio à Transgressão (1963a). Tradução: Inês Autran Dourado Barbosa. In: . Ditos e Escritos III: Estética: Literatura e Pintura, Música e Cinema. Rio de Janeiro: Forense Universitária, 2001. p. 28-46.

. A Linguagem ao Infinito (1963b). Tradução: Inês Autran Dourado Barbosa. In: . Ditos e Escritos, III: Estética: Literatura e Pintura, Música e Cinema. Rio de Janeiro: Forense Universitária, 2001. p. 47-59.

. O Que é um Autor? (1969). Tradução: Inês Autran Dourado Barbosa. In:___. Ditos e Escritos, III: Estética: Literatura e Pintura, Música e Cinema. Rio de Janeiro: Forense Universitária, 2001. p. 264-298.

Recebido em: julho de 2007

Aceito em: março de 2008 